\title{
PENGARUH LATIHAN HEXAGONAL OBSTACLE TERHADAP PENINGKATAN DAYA LEDAK POWER OTOT TUNGKAI
}

\author{
Achmad Nuryadi \\ Fakultas Keguruan dan Ilmu Pendidikan, Universitas PGRI Adi Buana Surabaya \\ email : caknuryadi@unipasby.ac.id
}

\begin{abstract}
Power is the power and speed of muscle contraction is dynamic and explosive and involves the expenditure of maximum muscle strength in the fastest time. Explosive power is one component of physical condition that is needed in sports. This is supported by the opinion of Sukadiyanto (2011: 128) power is the result of times between strength and speed. To that end, the sequence to increase power is given after the athlete is trained element of strength and speed. According to Riaydi, (2010) explosive power is a person's ability to use maximum capabilities deployed in the shortest time. The obstacle hexagonal jump is done quickly so that the movements performed are explosive or abrupt so as to have an effect on the increase of explosive muscle limb power. The result of statistical analysis showed that the mean for the treatment group was 2.90 while the mean for the control group was 1.55 this indicated that the mean group of threatment was greater than the control group. While the results of the threatment group analysis is known that the t-test value is 11.599 with the standard deviation of 1.119 and for the control group that the t-test value is 9.131 with the standard deviation of 0.759, thus there is indeed the effect of obstacle hexagonal exercise on increasing the muscle explosive power) leg muscles.
\end{abstract}

Keywords : Plyometrics workout and lay-up results

\section{PENDAHULUAN}

Olahraga bolabasket merupakan olahraga yang mulai digemari oleh semua kalangan, bahkan olahraga ini dapat disejajarkan dengan olahraga yang sudah lebih dulu populer di Indonesia seperti sepakbola dan bulu tangkis.

Untuk mencapai prestasi, ada empat aspek latihan yang perlu diperhatikan dan dilatih secara seksama oleh atlet, yaitu: 1) latihan fisik, 2) latihan teknik, 3) latihan taktik, dan 4) latihan mental (Harsono 1988: 100). Untuk itu seorang pelatih harus paham dan mengerti tentang aspek-aspek latihan tersebut untuk pencapaian hasil yang maksimal.

Ada beberapa macam komponen kondisi fisik, tetapi komponen kondisi fisik tersebut harus disesuaikan dengan cabang olahraganya, untuk cabang olahraga bolabasket atau cabang olahraga permainan yang lain seperti bolavoli dan sepakbola komponen kondisi fisik yang sesuai adalah kelincahan dan daya ledak. Harsono (2001: 22) menyatakan bahwa kelincahan adalah kombinasi dari kecepatan, kekuatan, kecepatan reaksi, keseimbangan, fleksibilitas, dan koordinasi neuromuscular. Daya ledak yaitu kemampuan seseorang untuk mempergunakan kekuatan maksimum yang dikerahkan dalam waktu yang sesingkatsingkatnya (Sajoto 1995: 17).

Harsono (1988: 100) mengatakan bahwa "beberapa komponen fisik yang perlu diperhatikan untuk dikembangkan adalah daya tahan kardiovaskuler, daya tahan kekuatan, kekuatan otot (strenght), kelentukan (flexibility), kecepatan, stamina, kelincahan (agility), power". Komponen-komponen kondisi fisi tersebut perlu adanya latihan yang sesuai dengan karakter dari cabang olahraga agar prestasi dapat tercapai atau ditingkatkan.

Power merupakan kekuatan dan kecepatan konstraksi otot yang dinamis dan eksplosif serta melibatkan pengeluaran kekuatan otot yang maksimal dalam waktu yang secepat-cepatnya. Daya ledak merupakan salah satu komponen kondisi fisik yang sangat diperlukan dalam cabang olahraga. Hal ini didukung oleh pendapat Sukadiyanto (2011:128) power adalah hasil kali antara kekuatan dan kecepatan. Untuk itu, urutan untuk meningkatkan power diberikan setelah olahragawan dilatih unsur kekuatan dan kecepatan. 
Lompatan hexagonal obstacle dilakukan dengan cepat agar gerakan yang dilakukan bersifat ekplosif atau tiba-tiba sehingga memberikan efek terhadap peningkatan daya ledak otot tungkai. Jika kaki bergerak dengan cepat maka dituntut kontraksi otot yang cepat pula karena kecepatan suatu gerakan dipengaruhi oleh kecepatan kontraksi otot. Pada dasarnya setiap dari bentuk latihan kekuatan dan kecepatan kedua-duanya selalu melibatkan unsur power. Dalam beberapa gerakan tubuh yang dinamis, seperti menendang, melempar, memindah tempatkan sebagian atau seluruh beban tubuh, daya ledak (power) ini sangat dibutuhkan

\section{KAJIAN LITERATUR}

Kecepatan merupakan kemampuan seseorang untuk mengerjakan gerekan kesinambungan dalam bentuk yang sama dengan waktu sesingkat-singkatnya. Menurut Sukadiyanto, (2011:116) kecepatan adalah kemampuan otot atau sekelompok otot untuk menjawab rangsangan dalam waktu yang secepat mungkin. Kecepatan sebagai hal perpaduan dari panjang ayunan tungkai dan jumlah langkah. Dimana gerakan panjang ayunan dan jumlah langkah merupakan serangkaian gerak yang sinkorn dan kompleks dari sistem neirumuskuler

Menurut Riaydi, (2010) daya ledak merupakan kemampuan seseorang dalam menggunakan kemampuan maksimum yang dikerahkan dalam waktu yang secepatnya. Dengan kata lain daya ledak otot adalah kekuatan (force) $\mathrm{x}$ kecepatan (velocity). Daya ledak adalah suatu kemapuan seseorang altlit untuk mengatasi suatu hambatan dengan kecpatan kontraksi yang tinggi. Daya ledak atau exsplosive power adalah kemampuan otot atau sekelompok otot seseorang untuk mempergunakan kekuatan maksimal yang dikerahkan dalam waktu singkat. Ini tercermin saat dalam aktifitas, tolak peluru lompat serta gerakan lain yang bersifat eksplosif. Daya ledak adalah hasil kali antara kekuatan dan kecepatan Sukadiyanto dalam Komang, (2012). Sedangkan menurut Harsono dalam Komang, (2012) mengatakan bahwa daya ledak adalah kemampuan otot untuk mengerahkan kekuatan maksimal dalam waktu yang sangat cepat. Daya ledak merupakan salah satu komponen kondisi fisik yang sangat diperlukan dalam cabang olahraga.

Latihan merupakan proses sistematis dari berlatih yang dilakukan secara berulangulang kian hari kian menambah jumlah beban latihanya. Diperlukan kondisi fisik yang baik untuk dapat melakukan kegiatan berulangulang sehingga fisik perlu dilatih terlebih dahulu. Untuk memperoleh prestasi yang maksimal dalam olahraga memerlukan latihan yang intensitasnya dan frekuensinya banyak.

\section{METODE PENELITIAN}

Jenis penelitian yang digunakan adalah penelitian kuantitatif. Metode penelitian yang digunakan adalah penelitian eksperimen, dan eksperimen yang digunakan adalah true experimental. Dikatakan true experimental (eksperimen yang betul-betul), karena dalam desain ini, peneliti dapat mengontrol semua variabel luar yang mempengaruhi jalannya eksperimen. (Sugiyono, 2009:75). Perlakuan berupa pemberian latihan hexagonal obstacle terhadap siswa sekolah menengah atas.

Dalam desain ini dibentuk kelompok eksperimen dan kelompok kontrol, sebelum percobaan kedua kelompok dipelajari untuk memperoleh data kuantitatif untuk membandingkannya. Kemudian diberi variabel eksperimen kepada kelompok percobaan akan tetapi tidak untuk kelompok kontrol. Adapun dalam penelitian ini menggunakan desain random group pre testpost test. Desain ini bentuknya sederhana, terdiri atas satu perlakuan dan satu kontrol, tetapi bisa dikembangkan menjadi beberapa perlakuan. (Ali Maksum, 2012:97)

Dalam penelitian ini digunakan teknik analisis data berupa T-test.

$$
\begin{array}{r}
=\frac{M_{x}-M_{y}}{\sqrt{\left(\frac{\sum x^{2}+\sum y^{2}}{N_{x}+N_{y}-2}\right)\left(\frac{1}{N_{x}}+\frac{1}{N_{y}}\right)}} \\
\quad \text { (Arikunto, 2006:331) }
\end{array}
$$

Keterangan :

$\mathrm{M}$ : Nilai rata-rata hasil perkelompok

$\mathrm{N}$ : Banyaknya subjek

$\mathrm{X}$ : Deviasi setiap nilai $\mathrm{X} 2$ dan $\mathrm{X} 1$

$\mathrm{Y}$ : Deviasi setiap nilai X2 dan mean X1 


\section{HASIL DAN PEMBAHASAN}

Hasil analisis secara statistik menggunakan Uji-t sehingga didapatkan hasil sebagai berikut:
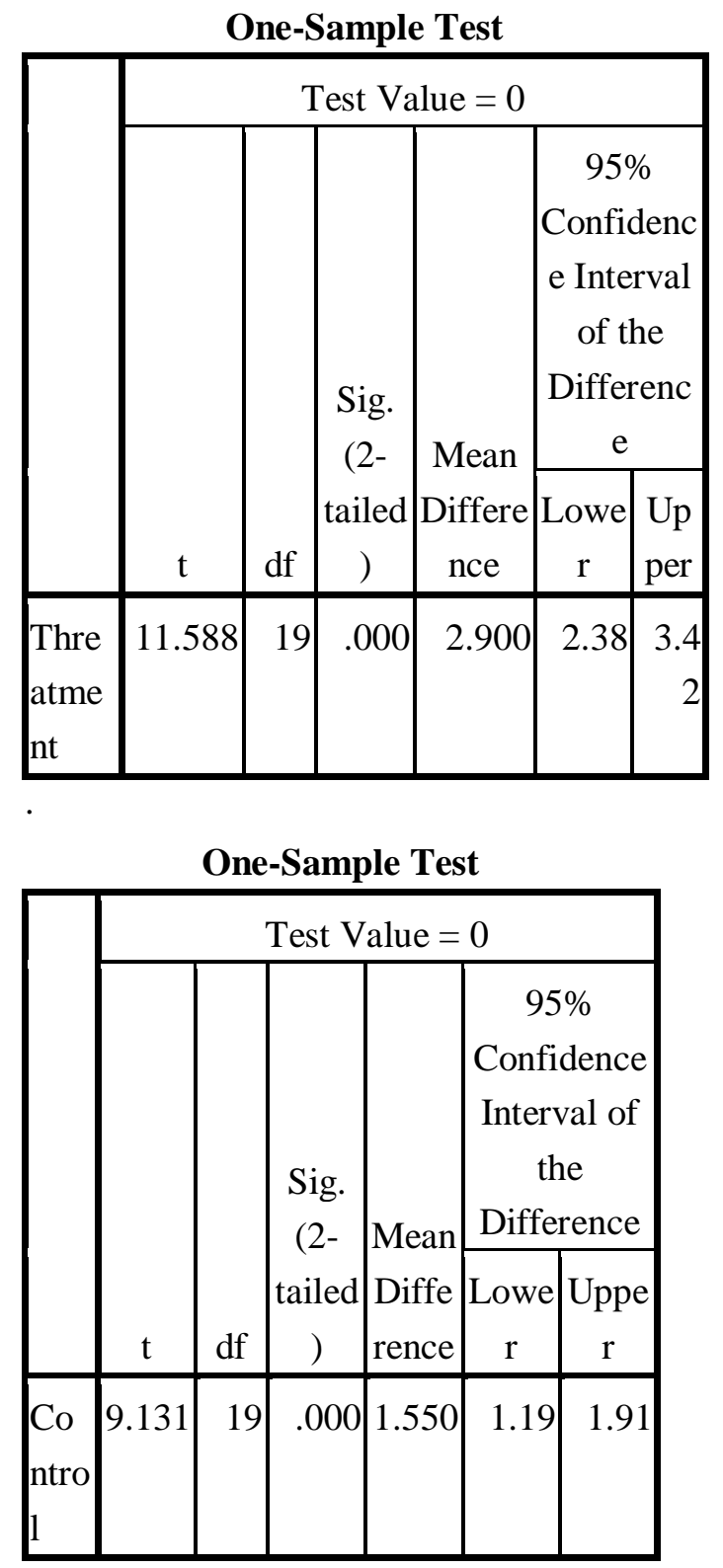

Dari tabel diatas dapat diketahui bahwa mean untuk kelompok treatment adalah 2,90 sedangkan mean u ntuk kelompok control adalah 1,55 hal ini menunjukkan bahwa hasil mean kelompok threatment lebih besar daripada kelompok control.

Dari tabel hasil analisis kelompok threatment diketahui bahwa nilai t-test adalah 11, 599 dengan standart deviasi 1,119, sedangkan untuk kelompok control bahwa nilai t-test adalah 9,131 dengan standarr deviasi 0,759 , dengan demikian Ho diterima sehingga hipotesis penelitian diterima, artinya benar ada pengaruh latihan hexagonal obstacle terhadap peningkatan daya ledak otot (power) otot tungkai.

\section{KESIMPULAN}

Dalam penelitian ini didapatkan hasil bahwa latihan hexagonal obstacle yang diberikan dapat meningkatkan daya ledak otot tungkai (power) pada siswa kelas X SMA Intensif Taruna Pembangunan Surabaya. Hal ini dibuktikan dengan hasil analisis statistik yang menunjukan bahwa mean untuk untuk kelompok treatment adalah 2,90 sedangkan mean u ntuk kelompok control adalah 1,55 hal ini menunjukkan bahwa hasil mean kelompok threatment lebih besar daripada kelompok control. Sedangkan hasil analisis kelompok threatment diketahui bahwa nilai ttest adalah 11, 599 dengan standart deviasi 1,119 dan untuk kelompok control bahwa nilai t-test adalah 9,131 dengan standarr deviasi 0,759, dengan demikian Ho diterima sehingga hipotesis penelitian diterima, artinya benar ada pengaruh latihan hexagonal obstacle terhadap peningkatan daya ledak otot (power) otot tungkai.

\section{REFERENSI}

Agung Nugruho, (2004). Diktat Pedoman Latihan Pencak Silat. Yogyakarta: FIK UNY.

Arikunto, Suharsimi. 2006. Prosedur Penelitian Suatu Pendekatan Praktik. Jakarta : Rineka Cipta.

Dr. Alebertus Fenanlampir, M.Pd., AIFO dan Dr. Muhammad Muhyi Faruq, (2014). Tes dan Pengukuran Dalam Olahraga. Ed.1.Yogyakarta.

Harre D. 2008. Principle Of Sort Training Introduction To Theory And Metode Training. Berlin : Versalg

Harsono. (1988) dalam Komang (2012). Coaching dan Aspek-Aspek Psikologis Dalam Coaching. Jakarta : Depdikdub Dirjen Dikti.

Ida Bagus Ketut Suryawan, I Nyoman Kanca, I Ketut Sudiana, 2014. pengaruh pelatihan lari sprint 60 meter dan hexagonal obstacle sprint terhadap peningkatan daya ledak otot tungkai. 
Ika Fitriyani, 2015. Pengaruh Latihan Plyometric Lompat Hexagon Dan Hop Scotch Terhadap Peningkatan Power Tungkai Pesilat Tapak Suci Remaja Kabupaten Klaten.

Muthohir, Toho Colick. 2006. Pelaksanaan Pendidikan Jasmani dan Olahraga di Indonesia Suatu Introspeksi. Media Pendidikan dan Ilmu Pendidikan No.46,XIII. Jakarta: Kemenegpora

Muriasa Komang, 2012. Pengaruh Pelatihan Hexagonal Obstacle Dan Sprint Side Hop Terhadap Daya Ledak (Power) Otot Tungkai

Nala, N. 2011. Prinsip Pelatihan Fisik Olahraga. Denpasar : UNUD Denpasar.

Nurhasan. (2006). Penilaian Pembelajaran Penjas.Jakarta : Depdiknas

Sukadiyanto. (2011). Pengantar Teori dan Metodologi Melatih Fisik. Bandung : Remaja. Rosda Karya.

Suriawan, Ida Ketut, dkk. 2014. Pengaruh latihan lari sprint 60 meter dan hexagonal obstacle sprint terhadap daya ledak otot tungkai. Jurnal ikor vol 1 no 1. Universitas Pendidikan Ganesha.

Suryawan Ida Bagus Ketut, dkk, 2014. Pengaruh Pelatihan Lari Sprint 60 Meter Dan Hexagonalobstacle Sprint Terhadap Daya Ledak Otot Tungkai.

Tamsir Riyadi,(2010). Petunjuk atletik. Yogyakarta: FPOK IKIP.

Tri Nurharsono. (2006). Tes Pengukuran Pendidikanjasmani dan Tes Kesegaran Jasmani Atlet.Semarang : PJKR FIK UNNES.

Widhiyanti, Komang Ayu Tri, dkk. 2013. Pelatihan pliomertik Alternate Leg Bound dan Double Leg Bound Meningkatkan Daya Ledak Otot Tungkai Pada siswa kelas VII SMP Negeri 3 Sukawati Tahun pembelajaran 2012/2013. Sport and fitness journal volume 1 no 2;19-26. Universitas Udayana. 